\title{
Ethnic Variations in Birth Weight - A Study of British, Chinese and Gurkha Babies
}

\author{
Major K P Jones \\ MA, MRCGP, RAMC(V) \\ ${ }^{*}$ RMO, 4 Kings Own Border
}

\begin{abstract}
All births at BMH Hong Kong during one year were analysed retrospectively according to ethnic group, birthweight, length and head circumference. Significant differences in birthweight were found between the groups and also between British babies born to service and civilian expatriate families.
\end{abstract}

\section{Introduction}

The identification of intra-uterine growth retardation is aided greatly by ultrasound, but depends on sound knowledge of normal ranges for birthweights. This information is readily available for white Caucasian babies but there are much less data for other ethnic groups. A recent study in the BMJ suggested using the ratio of mid-arm circumference to occipito-frontal circumference measured at birth as a means of bypassing ethnic variations. ${ }^{1}$ That study did not find significant differences in the birthweights of white, Asian and black babies, perhaps because of the small numbers involved. Other studies have looked at similar groups ${ }^{2,3}$, but there is little information on Gurkha and Chinese babies. The only published study of growth and nutrition in Nepali children, although detailed, relied on very small numbers. ${ }^{4}$ The present study is of previously unpublished data from the British Military Hospital in Hong Kong and predates a larger study by Jefferson and Taylor which examined perinatal mortality in Chinese and Gurkha babies. ${ }^{5}$ It demonstrates significant birthweight information not yet available elsewhere.

As an interesting side-issue, characteristics of babies born into British Service families are compared with those of babies born into civilian expatriate British families in Hong Kong.

\section{Methods}

Birth records of all babies born in the maternity unit at BMH Hong Kong during 1978 were examined retrospectively with records being made of ethnic group, sex of child, birthweight, head circumference and length. The British group was sub-divided into army and non-army families.

\section{Results}

Table 1 shows the breakdown by ethnic group and sex of the 934 births recorded in that year, and Table 2 shows the mean birthweight, head circumference and length in each group with standard deviations in brackets. The data was normally distributed and student's t-test was applied. The head circumference and weight of the $\vec{\omega}$ British babies was significantly greater than those of Gurkha ( $p<0.05 \& \mathrm{p}<0.005$ respectively) and Chinese babies ( $\mathrm{p}<0.001$ for both parameters). The Gurkle babies were significantly larger than the Chinese on for the same measurements $(\mathrm{p}<0.005 \&<0.001 \mathrm{t}$ respectively). Length measurements did not diffe significantly.

Table 1

Births in British Military Hospital Hong Kong in 1978

\begin{tabular}{lrcr}
\hline & Male & Female & Total \\
\hline British & 122 & 149 & 271 \\
Gurkha & 191 & 181 & 372 \\
Chinese & 133 & 146 & 279 \\
Others & 6 & 6 & 12 \\
\hline Total & 452 & 482 & 934 \\
\hline
\end{tabular}

Table 2

Birth Measurements by Ethnic Group

(Standard deviations in brackets)

\begin{tabular}{lccc}
\hline & Birthweight & Head circumference & Length \\
\hline British & (kilogrammes) & (centimetres) & (centimetres) \\
Gurkha & $3.345($ SD 0.524) & 34.73 (SD 1.63) & 50.83 (SD 5.67) \\
Chinese & $3.220($ SD 0.502) & $34.48($ SD 1.49) & 50.33 (SD 3.65) \\
\hline
\end{tabular}

* Now University of Southampton, Primary Medical Care.

.


Table 3

British Birth Measurements for Service and Civilian Families (Standard deviations in brackets)

\begin{tabular}{lcccc}
\hline & Number of Cases & Birthweight & Head circumference & Length \\
\hline & & (kilogrammes) & (centimetres) & (centimetres) \\
Army & 139 & 3.238 (SD 0.558) & 34.48 (SD 1.82) & 49.84 (SD 7.01) \\
Civilian & 129 & $3.460($ SD 0.461) & 34.99 (SD 1.35) & 51.90 (SD 3.45) \\
\hline
\end{tabular}

Table 3 compares the data on babies of British service personnel with non-service babies. Nine of the Army babies were small for dates (less than 2500 grams), giving a slight skew to those data, while none of the civilian babies was less than 2500 grams. Nevertheless application of student's t-test yielded the following figures: the Army babies were lighter $(p<0.001)$, shorter $p<0.005)$ and had smaller heads $(p<0.02)$ than the civilian neonates.

\section{Discussion}

The British group of babies with 122 males and 149 females represents a significant bias $(p=0.04)$ in favour of females when compared with the 1983 data for the Northern Region of England ${ }^{6}$. There were 39117 births in that year in the region with $51.5 \%$ males. Nevertheless, the bias in favour of females in this study is likely only to have lowered the actual mean value of the ethnic differences and does not cast doubt on their significance. As a further check on the data, the number of birthweights under $2500 \mathrm{~g}$ was identified in each group and was $3.3 \%$ for British, $3.5 \%$ for Chinese and $6.1 \%$ for Gurkha babies. The higher percentage of low birthweight in the Gurkha babies is interesting but does not alter the ranking of the three ethnic groups.

Thus it can be seen that provided a large enough series is used, useful reference data for normal birthweights can be found to aid in the assessment of intrauterine growth retardation. It would be most interesting to know if Jefferson and Taylor ${ }^{5}$ could derive similar figures from their larger and more recent study on the same population. Furthermore, it would be intriguing to compare babies born to Gurkha service personnel in Hong Kong with those born to families back in Nepal, so that an assessment of the role of maternal nutrition and its possible improvement in the military setting could be made. That study remains to be done.

The differences shown between army and civilian British babies raise some interesting speculations. It is likely that the social class structure of the two groups was very different with different standards of living and attitudes to health. However, it may also be one more reflection of the damage done by excess smoking known to occur in soldiers ${ }^{7}$ and by inference in their spouses. This finding warrants further investigation with health education measures in mind.

\section{Acknowledgement}

The author would like to thank Barbara Musgrave for her secretarial assistance.

\section{REFERENCES}

1. MEAdOWS $\mathrm{N}$ J et al. Screening for intrauterine growth retardation using ratio of mid-arm circumference to 8 occipito frontal circumference. Br Med $J$ 1986; 292: 1039-0 1040.

2. Alvear $\mathbf{J}$ and BroOke $O \mathrm{G}$. Fetal growth in differento racial groups. Arch Dis Child 1978; 53: 27-32.

3. Clarson C L et al. Secular change in birthweight of Asian babies born in Birmingham. Arch Dis Child 1982; 57: 867 . 871.

4. Farquharson $S \mathrm{M}$ Growth patterns and nutrition in Nepali children. Arch Dis Child 1976; 51: 3-12.

5. JeFFERSON T O and TAYLOR V M. Perinatal mortality in infants of two different ethnic groups. Family Practice $1985 ; 2: 175-176$.

6. O.P.C.S. S.D. 52. Vital Statistics 1983.

7. LYNCH $\mathrm{P}$ et al. Risk profile of soldiers aged under 40 with coronary heart disease. Br Med J 1985; 290: 1868-1869. 